\title{
Revista Eletrônica em Gestão, Educação e Tecnologia Ambiental
}

REGET/UFSM (e-ISSN: 2236-1170).

\section{EDUCAÇÃO AMBIENTAL PARA O DESENVOLVIMENTO LOCAL: UMA ALTERNATIVA PARA O DESENVOLVIMENTO DE MUNICÍPIOS}

\author{
Carla Cristiane Mueller', Clayton Hillig², \\ Wanderléia Elizabeth Brinckmann ${ }^{3}$, Ubirajara de Almeida ${ }^{f}$ \\ ${ }^{1}$ Bióloga e Licenciada em Ciências Biológicas pela UNISC, Pós Graduanda em Educação Ambiental pela UFSM - \\ naturalisgestao@hotmail.com \\ ${ }^{2}$ Professor do Departamento de Educação Agrícola e Extensão Rural do Centro de Ciências Rurais da Universidade \\ Federal de Santa Maria - hilig@smail.ufsm.br \\ ${ }^{3}$ Professora Drạ. do Departamento de Geografia da Universidade de Múrcia - ESPANHA webrin2001@yahoo.com.br \\ f Gestor Ambiental pela UNOPAR (Universidade do Norte do Paraná) naturalisgestao@hotmail.com.br
}

\section{RESUMO}

O Desenvolvimento Sustentável requer conhecimentos dos gestores públicos e privados, das associações comunitárias, dos sindicatos e de uma ferramenta fundamental de transformação da cultura e do conhecimento de uma sociedade que é o Professor. A qualificação dos gestores e educadores é fundamental para que possam, com ferramentas de participação, buscar junto à comunidade os objetivos que a mesma tem em relação ao futuro do município e sua relação com a região. Conforme Aziz $A B^{\prime}$ Saber, é fundamental que a escola proporcione aos seus alunos conhecimento local para o ensino fundamental, e regional para o ensino médio. "A educação é o meio pelo qual a criança se integra ao processo civilizatório e à sociedade. Ela deve ter três bases: o domínio do saber acumulado, as oficinas de talentos e o conhecimento da região" (Entrevista Revista Nova Escola - Edição 139 - Janeiro de 2001). Baseado nesta afirmação é fundamental que os gestores e professores tenham consciência de que somente o conteúdo programático não é o suficiente para que os alunos tenham o conhecimento necessário para que possam ocorrer mudanças de hábitos onde se comece a praticar a cultura do Desenvolvimento Local Sustentável. O conhecimento da região e as oficinas que proporcionam formas de aprimorar as qualidades e a real vocação da comunidade escolar são fundamentais para melhorar a qualidade de vida de uma comunidade e município. Após coletadas as informações de qualificação, quanto ao conhecimento de métodos de desenvolvimento local sustentável junto aos gestores, o Projeto pretende proporcionar oficinas de qualificação aos gestores, professores e lideranças dos municípios para estabelecer um programa de acompanhamento que terá como base o respeito a cultura local, a vocação da população e as condições geográficas e também ambientais de cada região.

Palavras-Chave: Saberes Locais, Educação, Desenvolvimento Local. 


\section{Revista Eletrônica em Gestão, Educação e Tecnologia Ambiental \\ REGET/UFSM (e-ISSN: 2236-1170).}

\section{ABSTRACT \\ ENVIRONMENTAL EDUCATION FOR THE LOCAL DEVELOPMENT: AN ALTERNATIVE FOR THE DEVELOPMENT OF MUNICIPALITIES}

THE Sustainable Development requires knowledge of the public managers and private, of the community associations, of the trade unions, and the a fundamental tool of processing of culture and knowledge of a society which is the Professor.

The qualification of the managers and educators, is fundamental to that can, with tools of participation, to get to the community the objetivos that the same is in relation to the future of the city and its relationship with the region. As Aziz AB'Saber, it is crucial that the school provides to their pupils local knowledge for the ensino fundamental, and regional for the middle school. "EDUCATION is the means by which the child is part of the process civilizatório and to society. It must have three bases: the area of knowledge accumulated and workshops of talent and the knowledge of the region" (Interview Revised New School - Edition 139 - Janeiro de 2001).

Based on this statement it is fundamental that the managers and teachers are aware that not only the programmatic content is not enough to students to have the knowledge to which may occur changes in eating habits where we can begin to pursue the culture of the Local Development Sustainable. THE knowledge of the region and the workshops that provide forms of implantado the qualities and the real purpose of the school community are fundamental to improve the quality of life of a community and the municipality. After coletadas em ninhos the information of qualification, in terms of knowledge of methods of local development sustainable in the managers, o Projeto is to provide and workshops of qualification to managers, teachers and leaders of the local authorities in order to draw up a work programme for monitoring that will be based on the respect the local culture, the vocation of the population and the geographical and environmental also of each region.

Keywords: Local Knowledge, Education, Local Development

\section{INTRODUÇÃO}

Neste trabalho nosso principal objetivo será analisar e discutir o papel da Educação Ambiental como uma ferramenta para a promoção do desenvolvimento local sustentável dos municípios de Candelária, Vale do Sol e Vera Cruz e neste sentido nos remetemos às leis que regem esta temática no Brasil e que serão nosso ponto de inicio do debate para a posteriori verificar se os planos e programas de EA dos municípios citados estão adequados a esta lei e se estes, cumprem com as normativas para alcançar o tipo de desenvolvimento proposto e desejado.

A região a que se refere esta pesquisa localiza-se no centro do Rio Grande do sul, região do Vale do Rio Pardo. Mais precisamente os Municípios com menos de 35.000 habitantes (Vera Cruz, Vale do Sol e Candelária) Figura 1. As propriedades rurais destes Municípios têm uma média de 16.9 hectares, dos quais grande parte destas propriedades se encontra em áreas de APPs, remanescentes da mata atlântica e relevo que dificulta a agricultura. A produção agrícola predominante é o tabaco, que mesmo com o aumento da tecnologia e produtividade está trazendo uma menor rentabilidade ao produtor rural. Outra cultura que está se acentuando na região é a 


\section{Revista Eletrônica em Gestão, Educação e Tecnologia Ambiental REGET/UFSM (e-ISSN: 2236-1170).}

silvicultura com espécies de Eucalipto que não é uma cultura anual ocupando solo fértil onde poderiam ser cultivadas outras culturas principalmente alimentícias. Estes fatores estão desestimulando os jovens na permanência no meio rural, os quais procuram por trabalhos no meio urbano e nas cidades maiores. A estrutura política e educacional destes municípios é frágil, o índice de desenvolvimento Municipal apontado nas áreas da educação, saúde, emprego e renda e as posições ocupadas por estas cidades diante do ranking no Rio Grande do Sul comprovam a potencialidade da região enquanto também alarmam para melhorias urgentes por estarem dentro do índice moderado de Desenvolvimento conforme a pesquisa da FIRJAN (Federação das Indústrias do Rio de Janeiro) atingindo entre 0,6 e 0,8 pontos (Figura 2, 3 e 4).

Conforme dita a Constituição Federal do Brasil, Lei 9.795/99, que institui a Política Nacional de Educação Ambiental e em seu Decreto regulamentador (4.281/02), esta deve proporcionar as condições para o desenvolvimento das capacidades necessárias para que grupos sociais, em diferentes contextos socioambientais, intervenham de modo qualificado, tanto na gestão do uso dos recursos ambientais, quanto na concepção e aplicação de decisões que afetam a qualidade do ambiente, seja físico-natural ou construído (QUINTAS, 2006 p 13).

Dias (2005) em seus escritos destaca que a Educação Ambiental por ser renovadora e capaz de induzir novas formas de conduta nos indivíduos e na sociedade, por lidar com as realidades locais, por adotar uma abordagem que considera todos os aspectos que compõem a questão ambiental - aspectos sociais, políticos, econômicos, culturais, éticos, ecológicos, científicos e tecnológicos, por ser catalisadora de uma educação para o exercício pleno e responsável de cidadania, pode e deve ser o agente otimizador de novos processos educativos que conduzam as pessoas por caminhos onde se vislumbre a possibilidade de mudanças e melhoria do seu ambiente total e da qualidade da sua experiência humana. Layargues (2004) destaca que por ser um processo educativo de cunho político a EA deve desenvolver a criticidade dos autores que com ela trabalham nas diferentes instituições (escolas, secretarias de governo, empresas)

Educação Ambiental é, portanto, um processo educativo eminentemente político, que visa ao desenvolvimento de uma consciência crítica acerca das instituições, atores e fatores sociais geradores de riscos e respectivos conflitos socioambientais. Busca uma estratégia pedagógica do enfrentamento de tais conflitos a partir de meios coletivos de exercício da cidadania, pautados na criação de demandas por políticas públicas participativas conforme requer a gestão ambiental democrática. (Layargues, 2004, p 10).

As ações de Educação Ambiental devem desenvolver o espírito crítico e a criatividade do cidadão quanto às alternativas locais de desenvolvimento sustentável, na busca de um ambiente saudável e ecologicamente equilibrado para as presentes e futuras gerações. Ela precisa estimular o envolvimento, a motivação dos agentes responsáveis pelo desenvolvimento do programa, a cooperação, a solidariedade e a parceria entre indivíduos, grupos e instituições, de forma a possibilitar ações integradas e compartilhadas pelos diversos segmentos da comunidade, atores principais desse processo. Assim sendo trabalhar a questão Social da Educação Ambiental é um elemento importante, que pode orientar o desenvolvimento de municípios.

Educação para uma vida sustentável envolve uma pedagogia centrada na compreensão da vida, uma experiência de aprendizagem no mundo real que supere a nossa alienação da natureza e reacenda o senso de participação e um currículo que ensine às nossas crianças os princípios básicos da sustentabilidade (CAPRA, 2002, p 44). 


\section{Revista Eletrônica em Gestão, Educação e Tecnologia Ambiental REGET/UFSM (e-ISSN: 2236-1170).}

\section{JUSTIFICATIVA}

O presente Projeto de pesquisa justifica-se pela necessidade de analisar e consolidar ações desenvolvidas no Vale do Rio Pardo em especial em três municípios: Candelária, Vale do Sol e Vera Cruz, com as quais já foram desenvolvidas atividades durante mais de quatro anos. $\mathrm{O}$ trabalho constante com estes municípios nos permite observar que continuam a existir: deficiências de informações relativas ao tema EA; uma grande quantidade de ações isoladas iniciadas por várias entidades e setores da sociedade que deveriam estar sistematizadas de forma a permitir ações concretas e permanentes que contribuíssem com o exercício da participação e da construção coletiva de uma alternativa de desenvolvimento sustentável em âmbito local (municípios) mais justa e igualitária para a população.

Entende-se, baseados em Capra (2002) que Educar para uma vida sustentável exige o desenvolvimento e aplicação de uma pedagogia educacional centrada na compreensão da vida, uma experiência de aprendizagem no mundo real que supere a nossa alienação da natureza e reacenda o senso de participação além de um currículo que permita ensinar aos educandos (crianças, jovens e adultos interessados) os princípios básicos da sustentabilidade.

Também justifica este projeto, a necessidade de recuperar os saberes locais (culturais, econômicos, ambientais e sociais) existentes em uma comunidade inserindo-os e integrando-os dentro do espaço escolar, através da prática pedagógica, para que assim os municípios possam se desenvolver melhor baseados no conhecimento popular, de acordo com sua vocação e na identidade cultural de sua população, garantindo o seu desenvolvimento local e sustentável.

\section{PROBLEMA DE PESQUISA}

De que forma gestores públicos e instituições de ensino utilizando os saberes locais podem contribuir através da prática da EA com o desenvolvimento local sustentável?

\section{OBJETIVOS}

\subsection{Geral}

O principal objetivo deste trabalho é verificar e classificar o real conhecimento que os gestores educacionais, Secretários de Educação, orientadores educacionais e principalmente os professores têm sobre os conceitos de Desenvolvimento Local e Desenvolvimento Sustentável e sua aplicabilidade no espaço escolar em programas interdisciplinares de EA. Analisar as ações e/ou programas educacionais que os Municípios estudados (Candelária, Vera Cruz e Vale do Sol) têm para alcançar o seu desenvolvimento local e regional.

\subsection{Objetivos Específicos}

3.2.1 Verificar se existe correlação e integração entre os programas e projetos de EA da secretaria de educação e das escolas municipais, com as outras secretarias e a sociedade civil dentro dos municípios pesquisados;

3.2.2 Investigar sobre a interferência dos saberes locais, das características culturais, hábitos e costumes de uma comunidade no desenvolvimento de um município; 


\section{Revista Eletrônica em Gestão, Educação e Tecnologia Ambiental \\ REGET/UFSM (e-ISSN: 2236-1170).}

3.2.3 Fomentar a implantação de projetos sistemáticos em Educação Ambiental no processo escolar, que trabalhem uma articulação entre os saberes locais e o meio ambiente das comunidades que ali vivem, com vistas à transferência de informações e desenvolvimento de capacidades, hábitos e atitudes para assegurar a qualidade de vida da população.

3.2.4 Construir um mapa conceitual que oriente o desenvolvimento de um Projeto de Educação Ambiental numa escola direcionando-o para a busca dos saberes locais em uma comunidade e assim para o desenvolvimento local.

\section{REFERENCIAL TEÓRICO}

Alguns dos conceitos básicos que destaca Jacobi (2004) e que os educadores ambientais deverão incorporar para que lhes seja possível uma interpretação adequada da realidade e que, ao mesmo tempo, venham a constituir-se em elementos básicos do novo paradigma emergente são os conceitos de estrutura, de sistema como um todo, que juntos compõe as etapas para o desenvolvimento de uma região. Nesta nova abordagem o sistema teórico a ser aplicado que por sua condição e objetivos manifesta a mais ampla transdicisplinaridade, se fundamenta na idéia de que o conjunto de acontecimentos observáveis apresenta estruturas coerentes, está baseado na construção coletiva do conhecimento, na ação reflexiva e consciente e nas mudanças éticas de comportamentos tendentes a concretizar processos de tomada de decisões participativas e democráticas: Permite ademais a compreensão das repercussões das condições atuais da educação, nas relações sociais, nos processos de análise crítica, de reflexão e de gestão socioambiental (BRINKMANN, W \& MUELLER C.C., 2010)

De forma que, sob um novo olhar ético, a educação ambiental deve se estabelecer como um processo que consista em propiciar às pessoas uma compreensão crítica e global do meio ambiente, para que elas possam desenvolver valores e atitudes que lhes permita adotar uma posição crítica e participativa a respeito das questões relacionadas com a conservação e a adequada utilização dos recursos naturais, visando-se a melhoria da qualidade de vida e a eliminação da pobreza extrema e do consumismo desenfreado, a construção de relações sociais, econômicas e culturais capazes de respeitar e incorporar as diferenças, e a liberdade para decidir na busca de caminhos alternativos de desenvolvimento (MEDINA, 2002). Nessa perspectiva, será sumamente importante:

- Compreender a natureza sistêmica e complexa do meio resultante da interação de aspectos biológicos, físicos, sociais, econômicos e culturais;

- Revisar atitudes e valores a respeito do meio ambiente, para reorientar as posições éticas que sustentam a ação, como a prática da tomada de decisões;

- Vincular desenvolvimento ao meio ambiente;

- Participar na construção dos ideais coletivos.

Educação Ambiental é antes de tudo educação, não uma educação no sentido genérico, mas aquela que se nutre de pedagogias orientadas para a transformação social, devendo, portanto, estar contextualizada nas práticas sociais e presente em todos os espaços que educam o cidadão.

Considerando Morin (1992), devemos ter a visão da globalidade, do intercâmbio, da interdisciplinaridade que nos permitem a comunicação com a sociedade. Conforme o autor, tudo 


\section{Revista Eletrônica em Gestão, Educação e Tecnologia Ambiental REGET/UFSM (e-ISSN: 2236-1170).}

no universo está ligado: pátria, nação, universalidade, identidade, ecologia, política, comunidade, sendo impossível tratar de forma retalhada o que é tecido junto.

Segundo os autores consultados e a prática desenvolvida em atividades e programas de EA cometemos todos os educadores e gestores, um grande equívoco ao tratar como um mero amontoado de elementos ao Meio Ambiente, que é um sistema complexo. De forma que tomar consciência de que o verdadeiro objetivo do desenvolvimento é melhorar a qualidade de vida das pessoas. É um processo que torna possível aos seres humanos perceberem o seu potencial, obter autoconfiança e uma vida plena, com dignidade e satisfação. O crescimento econômico é um importante componente do desenvolvimento, porém não pode ser um objetivo isolado, nem tampouco prosseguir indefinidamente. O desenvolvimento só é verdadeiro quando melhorar a nossa vida em todos os seus aspectos e a Educação Ambiental deve estar direcionada a este objetivo (FREIRE, C. C. DE OMENA, 2009).

Há certo esquecimento dos professores em relação às potencialidades de seus estudantes em sala de aula, esquecendo-se de que são capazes de recriar o conhecimento, como enfoca Attico Chassot "é preciso abandonar a assepsia. Há necessidade de tornar o nosso ensino mais sujo, isto é, encharcá-lo na realidade" (CHASSOT, 2001, p. 98), o que mostra a real necessidade de mudar nossas práticas enquanto professores e aproximar a matéria ensinada da realidade de cada região, buscar conhecer o que cerca o aluno, seu conhecimento já adquirido, necessidades e saber transformá-las em conteúdo didático. Muitas vezes, o estímulo para o aluno estudar, deve vir fundamentalmente do seu envolvimento com a proposta de trabalho da escola, como destaca (VASCONCELOS, 1998), o que pode ser reforçado quando ocorre participação efetiva no momento da construção da mesma, levando maior motivação ao estudante, e deixando claro para ele que estudar é bom, saudável e pode ajudá-lo a melhorar a sua própria vida na comunidade. A alfabetização científica pode ser considerada como uma das dimensões para potencializar alternativas que privilegiem uma educação mais comprometida, mais aberta e voltada para a natureza como um todo. Attico Chassot (2001) em seu livro sobre a concepção da ciência e do método científico afirma que devem ter uma linguagem, um conjunto de conhecimentos que facilite aos homens e mulheres fazer a leitura do mundo onde vivem.

Insisto em expor as colocações de Attico Chassot neste trabalho, pois o mesmo compara a falta de iniciativas científicas com a extinção de sementes caipiras, ou seja, ele explica que a busca de saberes populares que estão em extinção devem virar saberes escolares. Este autor defende uma alternativa de ensino mais impregnado com posturas mais holísticas, isto é com um ensino de Ciências que contemple aspectos históricos, dimensões ambientais, posturas éticas e políticas, encharcadas na procura de saberes populares para fazê-los saberes escolares. Os professores devem estar cada vez mais preparados para reelaborar as informações que recebem, dentre elas, as ambientais, a fim de poderem transmitir e decodificar para os alunos a expressão dos significados sobre o meio ambiente e a ecologia nas suas múltiplas determinações e interseções. A ênfase deve ser a capacitação para perceber as relações entre as áreas como um todo, enfatizando uma formação local e global, buscando marcar a necessidade de enfrentar a lógica da exclusão e das desigualdades.

As escolas trabalham geralmente com atividades formais, com temas geradores predominantemente como lixo, proteção do verde, degradação dos mananciais, para fazer acontecer à interdisciplinaridade, mas, o que se pretende com a Educação Ambiental na escola, é que ela seja um processo de permanente aprendizagem, que valoriza as diversas formas de conhecimento e constitua cidadãos com consciência local e uma visão do planeta, com atividades 


\section{Revista Eletrônica em Gestão, Educação e Tecnologia Ambiental REGET/UFSM (e-ISSN: 2236-1170).}

muito além das formais. Da mesma forma o Geógrafo Aziz AB'Saber (REVISTA NOVA ESCOLA, JUNHO 2001, p 5) diz “A Educação Básica deveria preocupar-se em incentivar o aluno a construir o conhecimento da região em que vive, então a escola, com o consentimento da gestão escolar e a participação da comunidade escolar, tem que planejar o que querem e o que devem seus filhos aprender da região, para qualificar a vida na comunidade em que vivem. Sem conhecer o ambiente em que vivem, não saberão cuidá-lo.

O mesmo autor explica enfaticamente que a Educação ambiental é uma coisa mais séria do que geralmente tem sido apresentada em nosso meio. É um apelo à seriedade do conhecimento e, uma busca de propostas corretas de aplicação de ciências. Uma "coisa" que se identifica com um processo. Um processo que envolve um vigoroso esforço de recuperação de realidades e de construção conjunta do futuro da comunidade local, o que não é nada simples. Uma ação, entre missionária e utópica, destinada a reformular comportamentos humanos e recriar valores perdidos ou jamais alcançados. Um esforço permanente de reflexão sobre o destino do homem, de todos os homens, em face de harmonia das condições naturais e o futuro do planeta "vivente", por excelência. Um processo de Educação que garante um compromisso com o futuro. Envolvendo uma nova filosofia de vida. E, um novo ideário comportamental, tanto em âmbito individual, quanto na escala coletiva.

Enfim, Educação Ambiental exige método e conhecimentos sobre diferentes realidades regionais. São, sobretudo, códigos de linguagem adaptados às faixas etárias do alunado. É um processo que, necessariamente, revitaliza a pesquisa de campo, por parte dos professores e dos alunos. Implica em um exercício permanente de interdisciplinaridade. Nesse sentido, a Educação Ambiental, bem conduzida, colabora efetivamente para aperfeiçoar um processo educativo maior, sinalizando para a conquista ou reconquista da cidadania. É a nova "ponte" entre sabedoria popular e a consciência técnico-científica. Assim afirma Aziz Ab'Saber (REVISTA NOVA ESCOLA, JUNHO DE 2001, p 5) “A educação ambiental obriga-nos a um entendimento claro sobre a projeção dos homens em ambientes terrestres, herdados da natureza e da história. O lugar de cada um nos espaços remanescentes de uma natureza modificada; o lugar de cada um nos espaços sociais criados pelas condicionantes socioeconômicas. No balanço de fim de século, restaram poucas contribuições positivas para garantir o futuro da humanidade. A educação ambiental, será, com toda certeza, um dos poucos instrumentos com maior ressonância para defesa da vida. E, para a reeducação dos pais através da consciência cultural de uma juventude que não admite o imediatismo, odeia a guerra e cultua a justiça social".

\section{METODOLOGIA}

Para trabalhar com este projeto faremos uso de metodologias de cunho participativo e social porque entendemos que com o desenvolvimento de suas exigências metodológicas, as propostas de pesquisa alternativa (participativas e de ação comprometida e responsável) poderão vir a desempenhar um importante papel nos estudos e na aprendizagem dos pesquisadores e de todas as pessoas ou grupos implicados em situações ambientais problemáticas. Trata-se de facilitar a busca de soluções aos problemas sócioambientais reais para os quais os procedimentos convencionais tem pouco contribuído. Devido à urgência de tais problemas (educação, informática, práticas políticas) os procedimentos escolhidos devem obedecer a prioridades estabelecidas a 


\title{
Revista Eletrônica em Gestão, Educação e Tecnologia Ambiental REGET/UFSM (e-ISSN: 2236-1170).
}

partir de um diagnóstico da situação, no qual os participantes tenham voz e vez. (THIOLLENT, 1992).

\begin{abstract}
Neste sentido, a pesquisa ação é um tipo de pesquisa social com base empírica que é concebida e realizada com estreita associação com uma ação ou com a resolução de um problema coletivo no qual os pesquisadores e os participantes representativos da situação estão envolvidos de modo cooperativo e participativo (THIOLLENT, 2002,p 60).

Isso significa que a ação é sempre intencional, a intencionalidade é sempre política e a ação política democrática só pode ser construída com participação real e concreta dos sujeitos sociais e históricos envolvidos (GAJARDO, 1999, p 16).
\end{abstract}

Iniciamos a pesquisa, com a análise dos planos de estudos que orientam o processo escolar nas Secretarias de Educação de cada um dos municípios, na procura de dados e elementos dos programas de ensino que abordavam a Educação Ambiental. Também realizamos entrevistas com alguns gestores escolares (secretários de educação, supervisores) que participam da organização do currículo escolar.

Com o objetivo de encontrar respostas para as perguntas que estávamos colocando no círculo de debates, reunimos os profissionais da educação através da realização de oficinas em cada município estudado. Estas oficinas foram realizadas no intuito de questionar os professores sobre o processo escolar e o método de ensino utilizado para atingir o desenvolvimento local sustentável nos municípios. Depois de promover uma discussão sobre o referido tema e dividir os participantes em grupos foram lançadas algumas perguntas chaves para desafiá-los:

1- "Como podemos melhorar a nossa atuação como profissionais e caminhar rumo ao desenvolvimento de nosso município"

2- "Os projetos de Educação Ambiental desenvolvidos, abordam a realidade ambiental de cada localidade do município? Apontam problemas e criam soluções?"

\section{3- "Como funcionam os projetos junto á comunidade escolar? Eles interagem com as pessoas?"}

4- "Como uma educação voltada ao meio em que vivemos pode contribuir para o desenvolvimento local sustentável de um município?

Usamos como ferramenta metodológica um debate entre os participantes a partir da criação de grupos de trabalho (quatro integrantes em cada grupo, que debatem entre si e assim sucessivamente com todos os outros grupos), e da Plenária para apresentar suas contribuições. Ambas as ferramentas foram empregadas para compartilhar as informações e coletar os dados para o estudo.

\section{RESULTADOS E DISCUSSÕES}

\subsection{Desenvolvimento Local e Desenvolvimento Sustentável}

O Desenvolvimento Sustentável é alicerçado sob três princípios básicos para existir: 0 desenvolvimento econômico através da geração de lucros, o desenvolvimento social, através do aumento da qualidade de vida das pessoas e da igualdade social e principalmente pela 


\section{Revista Eletrônica em Gestão, Educação e Tecnologia Ambiental REGET/UFSM (e-ISSN: 2236-1170).}

conservação do meio ambiente onde se inserem as pessoas, partes importantes deste processo.

O desenvolvimento deve satisfazer condições de sustentabilidade em relação á cada uma das cinco dimensões: Econômica, social, cultural, política e ecológica. Preservar de forma absoluta a natureza em detrimento dos valores, aspirações e qualidade de vida dos seres humanos não é sustentável (PHILIPPI, 2002, p 80).

O desenvolvimento local sustentável é, portanto, um processo que leva a um continuado aumento da qualidade de vida com base numa economia eficiente e competitiva, com relativa autonomia das finanças públicas, combinado com a conservação dos recursos naturais e do meio ambiente (JACOBI, 2006, p 67). As experiências bem-sucedidas de desenvolvimento local (endógeno) decorrem, quase sempre, de um ambiente político e social favorável, expresso por uma mobilização, e principalmente, de convergência importante dos atores sociais do município ou comunidade em torno de determinadas prioridades e orientações básicas de desenvolvimento. Representa, neste sentido, o resultado de uma vontade conjunta da sociedade que dá sustentação e viabilidade política a iniciativas e ações capazes de organizar as energias e promover a dinamização e transformação da realidade. $\quad 0$ desenvolvimento local sustentável é o "processo de mudança social e elevação das oportunidades da sociedade, compatibilizando, no tempo e no espaço, o crescimento e a eficiência econômica, a conservação ambiental, a qualidade de vida e a eqüidade social, partindo de um claro compromisso com o futuro e a solidariedade entre gerações (Buarque, 1994: p 17).

Acrescento á estes conceitos um meio termo, uma idéia para modificar alguns aspectos de uma cidade, município ou localidade, um grande exemplo e parâmetro que permeia a discussão sobre Desenvolvimento Sustentável e Desenvolvimento local. "Trata-se de um movimento internacional de organização da sociedade civil, catalisador de uma transformação para melhorar. É um movimento que engaja a sociedade sob ponto de vista político, econômico ou religioso, não desce de nenhuma hierarquia para acontecer, é dado e colocado na mão do povo e viável em qualquer local, rural e urbano, porque promove a troca de recursos entre as pessoas, incentivando uma interação maior. A base é trazer as pessoas para promover decisões porque todos somos importantes. A idéia é evoluir de uma forma viral, quanto mais ações estratégicas e foco linear, mais fortes seremos. Estes são os ensinamentos do Movimento Transitions Tows - Cidades em Transição, fundado por Rob Hobkins em 2006, estimulado pelo mundo todo e com várias ações em cidades brasileiras que considera o fortalecimento das comunidades como o fator mais importante para a definição de um novo modelo de desenvolvimento" (Revista Planeta, junho de 2011, p 7 e 8).

Com um foco, no Desenvolvimento Local dos três municípios que fazem parte desta pesquisa, partimos para a abordagem de seus conceitos e investigamos junto á base da educação, os docentes e gestores escolares, como que enfrentam este desafio e se acreditam que o município possa se desenvolver localmente e com sustentabilidade. Segundo as respostas dos profissionais da educação sobre como poderiam contribuir para desenvolver os seus municípios estes afirmaram que a sua contribuição já é enorme porque estavam ensinando as gerações novas e que num futuro próximo seriam eles os governantes, as pessoas influentes ou até mesmo os habitantes que trabalhariam para melhorar as condições de qualidade de vida. Durante as oficinas comentaram que toda responsabilidade sempre recaia sobre o professor, é sempre ele a pessoa responsável por induzir metodologias que geram resultados nos municípios, as demais pessoas e profissionais são automaticamente excluídas deste processo. 


\title{
Revista Eletrônica em Gestão, Educação e Tecnologia Ambiental REGET/UFSM (e-ISSN: 2236-1170).
}

Alguns destes educadores em conversas colaterais expressaram seus anseios em reinventar o processo educativo para tal propósito, pediram ajuda e orientação para seguir com o desafio. Isto nos leva ao único modo capaz de dar suporte a estes profissionais, a Educação Ambiental, porque segundo a Conferência de Internacional do Meio Ambiente, realizada na Grécia em 1997,

\begin{abstract}
A reorientação da educação como um todo com vistas á sustentabilidade envolve todos os níveis de educação, formal, informal em todos os países. O conceito de sustentabilidade compreende não somente o meio ambiente, mas também pobreza, população, saúde, segurança alimentar, democracia, direitos humanos e paz. A sustentabilidade é em última análise, um imperativo moral e ético no qual a diversidade cultural e o conhecimento tradicional precisam ser respeitados (PHILIPPI, 2002, p 81).
\end{abstract}

\subsection{Meio Ambiente e Ecologia}

Pela complexidade de problemas que o meio ambiente enfrenta, é muito válido que os municípios passem por experiências de Educação Ambiental, onde através de muito planejamento as ações se voltem para as relações ecológicas entre o homem e a natureza. Na descrição básica do conceito de Ecologia, obtêm-se vários conceitos, mas para esta pesquisa parte-se do princípio da interação entre Ecologia e Antropologia, que podem ser definidas como:

\footnotetext{
Parte da Biologia que estuda as relações entre os seres vivos e o meio ou ambiente em que vivem, bem como suas recíprocas influências. Ramo das ciências humanas que estuda a estrutura e o desenvolvimento das comunidades humanas em suas relações com o meio ambiente e sua conseqüente adaptação a ele, assim como os novos aspectos que os processos tecnológicos ou os sistemas de organização social possam acarretar para as condições de vida do homem (Ferreira, 1975, p 12).
}

Um bom começo para discutir problemas ambientais em uma comunidade são os Conselhos Municipais de Meio Ambiente que colaboram para a formulação da política municipal de proteção ao meio ambiente através de planos, projetos, programas e diretrizes que regem as leis ambientais do município. Os três municípios estudados possuem seus planos ambientais, onde diagnosticam problemas e apresentam medidas de controle em relação ao meio ambiente. Como especifica o Plano Ambiental do Município de Vale do Sol,

\footnotetext{
Este Plano é um instrumento que o órgão público municipal e a população têm a sua disposição para promover o desenvolvimento econômico e social e a conservação do seu patrimônio ambiental. Ele ficará disponível para consulta por qualquer pessoa ou órgão governamental ou não-governamental. Haverá participação ativa, acompanhamento e fiscalização das determinações e condições contidas em qualquer estudo ambiental para a implantação e/ou licenciamento ambiental de projetos no âmbito do município de Vale do Sol (Plano Ambiental Município Vale do Sol, p 2).
}

É indispensável o aprofundamento do Plano com seus projetos propostos com a comunidade, no sentido de avaliar os seus objetivos, bem como, a introdução de novas metodologias no que se refere à abrangência do mesmo, sendo assim, todas as demandas que surgirem na dinâmica de desenvolvimento do município, no que se refere ao meio ambiente, 


\section{Revista Eletrônica em Gestão, Educação e Tecnologia Ambiental REGET/UFSM (e-ISSN: 2236-1170).}

estando ou não contempladas no Plano Ambiental que envolvam pessoas ou comunidades, serão sempre decididas em audiências públicas.

É importante retomar a necessidade de investir na capacitação dos agentes de transformação. Em nível municipal, onde os problemas se cristalizam sob forma de degradação ambiental, assiste-se a um total desconhecimento das autoridades quanto aos problemas básicos da comunidade e isto dificulta a possibilidade de investimentos em infra estrutura básica que são praticamente dependentes de verbas federais e estaduais.

A inserção da dimensão ambiental, no sistema educativo exige um novo modelo de professor que seja agente transformador da sua própria prática de ensinar, ou seja, que adote o processo de educação na perspectiva da interdisciplinaridade (SATO, 2003, p 24).

Todas as ações ambientais perpassam pela Educação, devido à integração entre Escola, Estudantes e Comunidade. Proporcionar a toda a população as informações pertinentes no que se refere às questões ambientais, que possam reduzir os impactos para melhorar a qualidade de vida de todos, é papel primordial da escola. Estabelecer um processo de gestão, de forma integrada, descentralizada e participativa, das atividades socioeconômicas do município, de modo a contribuir para elevar a qualidade de vida de sua população e a proteção de seu patrimônio natural, histórico, étnico e cultural também perpassa pelo papel fundamental da escola.

\subsection{Educação Ambiental e o Currículo Escolar}

A relação entre a escola e a comunidade - por vezes tensa e delicada, visto que é uma relação de poder - se estabelece também no reconhecimento da necessidade do estabelecimento de políticas socioculturais, a serem implementadas pelo empenho de todos os educadores, dentro e fora da escola, com a participação de políticas intersetoriais e intergovernamentais. Ao mesmo tempo, conseguir diminuir a distância entre a escola e a vida tem sido um desafio percorrido por muitos educadores, em diferentes tempos, desde o surgimento da escola até os dias de hoje.

Parafraseando a Moll (2004) entendemos que devemos construir espaços educadores em todos os âmbitos do município porque somente assim poderemos consolidar os princípios compreendidos no projeto da Cidade Educadora, na qual coexistem a cidade e o entorno como locais ricos e flexíveis, que ofertam inúmeras possibilidades de convivência e cidadania. Em seus artigos o autor explica que,

[..] a compreensão da cidade como uma grande rede ou malha de espaços pedagógicos formais (escolas, creches, faculdades, universidades, institutos) e informais (teatros, praças, museus bibliotecas, meios de comunicação, repartições públicas, igrejas, além do trânsito, do ônibus, da rua) que, pela intencionalidade das ações desenvolvidas, pode converter a cidade em território educativo, pode fazer da cidade uma pedagogia (MOLL, 2004, p 42).

Depreende-se dos debates com os educadores dos municípios envolvidos neste trabalho que o projeto a ser desenvolvido deve estar comprometido com a transformação da sociedade e a formação de cidadãos e neste sentido, o diálogo é uma das ferramentas mais eficazes. Além de reconhecer as diferenças, qualquer programa ou projeto de EA, precisa promover igualdades e estimular os ambientes de trocas em um projeto integrado e aberto, intercultural, que dê conta da complexidade do mundo contemporâneo. Nessa direção, já há experiências bem sucedidas acontecendo no Brasil, revelando a diversidade na operacionalização da Educação Ambiental. 


\section{Revista Eletrônica em Gestão, Educação e Tecnologia Ambiental REGET/UFSM (e-ISSN: 2236-1170).}

De forma bem inicial, estamos propondo neste trabalho, uma reflexão sobre nossos exercícios diários de formação do indivíduo. O que acreditamos? A que comportamentos devemos nos opor? Que sociedade queremos ajudar a (re)formar? Por que precisamos uma educação específica direcionada ao meio onde vivemos? Seria a Educação Ambiental capaz de responder a estes anseios? A Educação Ambiental objetiva integrar estes diversos campos do saber em uma prática educativa interdisciplinar capaz de contribuir para a compreensão de cidadãos da realidade complexa da questão ambiental?

Neste espaço fazemos usos das contribuições dos gestores escolares e professores do município de Vale do Sol, que reunidos em cinco grupos discutiram sobre como poderiam ensinar melhor e estimular o processo educativo do município. Os grupos chegaram às seguintes conclusões:

\section{Quadro 1: Sugestões por Grupo de Professores}

\begin{tabular}{|l|l|}
\hline GRUPO 1 & $\begin{array}{l}\text { Trabalho em rede; Capacitação do professor; Despertar } \\
\text { do saber; Motivação Mútua (família, escola e aluno); } \\
\text { Envolver e resgatar valores; Respeito professor e aluno; } \\
\text { Aceitação no grupo. }\end{array}$ \\
\hline GRUPO 2 & $\begin{array}{l}\text { Currículo diversificado; Políticas públicas efetivas; } \\
\text { Tecnologias eletrônicas; Escolas sociais }\end{array}$ \\
\hline GRUPO 3 & $\begin{array}{l}\text { Mais investimentos financeiros em Projetos; } \\
\text { Comprometimento da família; } \\
\text { Espaço físico e Recursos Humanos }\end{array}$ \\
\hline GRUPO 4 & $\begin{array}{l}\text { Montar parcerias (pais e agentes comunitários); } \\
\text { Contextualizar as atividades conforme a realidade. }\end{array}$ \\
\hline GRUPO 5 & $\begin{array}{l}\text { Responsabilidade; Comprometimento; Conhecimento, } \\
\text { Apreensão de comportamentos; Modificação atitudes; } \\
\text { Evolução da sociedade. }\end{array}$ \\
\hline
\end{tabular}

Fonte: Oficinas de trabalho, 2011

\subsection{Definição de Espaço Escolar}

$\mathrm{Na}$ "disponibilidade para o diálogo", no sentido usado por Freire (1996 p 153), de "abertura respeitosa aos outros", é possível potencializar todos os agentes educativos enquanto instituições formadoras. Desta forma, a escola poderá ser afetada positivamente pelas práticas comunitárias, pela liberdade e autonomia presentes nos espaços de educação informal, pela concretude e pelo movimento da vida cotidiana.

As propostas dos grupos e dos autores consultados, apontam para a necessidade de enxergar a educação para além da escola, articulando diversos atores e instituições locais na construção de redes que se co-responsabilizem pela educação das crianças e dos jovens. Sob essa 


\section{Revista Eletrônica em Gestão, Educação e Tecnologia Ambiental REGET/UFSM (e-ISSN: 2236-1170).}

ótica, as cidades emergem com importância crescente na construção de novas formas de sociabilidade e interações, com seus múltiplos espaços de conhecimento e múltiplas oportunidades de aprendizagem, na construção de uma prática pedagógica interdisciplinar voltada à resolução de problemas de uma comunidade, busca de respostas e curiosidades que geram o conhecimento, concretização de ações efetivas de transformação da realidade social.

A experiência metodológica desenvolvida pela Escola da Ponte de Portugal nos serve como exemplo para construir nossas próprias atividades: "Em cada escola, há um Professor Comunitário com a tarefa de coordenar o conjunto de ações que lhe são atribuídas. Esse professor organiza a matriz curricular, em consonância com o projeto político-pedagógico, mediante consulta aos professores da escola. As atividades indicadas na matriz são desenvolvidas por universitários ou por agentes culturais. Essa escolha envolve também uma consulta a um "cardápio" de oficinas oferecidas pelas universidades, pelos agentes culturais da comunidade e por organizações não governamentais. A Educação Integral articulada a um projeto de cidadania está, também, intimamente, ligada a um projeto político-pedagógico de escola construído democraticamente, com a participação da comunidade" (JOSÉ PACHECO, PALESTRA EM 2011 UNISC/RS)

É necessário reiterar o papel de centralidade e de protagonismo da escola, cuja relevância social e política deverão promover a articulação entre todos os agentes sociais que demonstram potencial educativo. Isto envolve romper com o tradicional isolacionismo da escola, prevendo uma disposição para o diálogo e para a construção de um projeto político-pedagógico que contemple princípios e ações compartilhados nos municípios.

Admitindo as condições socioeducativas favoráveis do entorno - comunidade local, cidade - e das suas condições de articulação com a escola, balizados pela centralidade do projeto políticopedagógico, é plenamente possível projetar um melhor aproveitamento escolar, ou seja, uma melhoria na qualidade das aprendizagens formais e das possibilidades de estabelecimento de relações dos conhecimentos com a vida diária dos estudantes.

Nos currículos escolares analisados nos três municípios pesquisados obteve-se uma demonstração daquilo que as crianças aprendem na escola (que não está trabalhando sob o enfoque do espaço escolar), que funcionam automaticamente, sem interferência da gestão, como é o caso das escolas multiseriadas. Estas escolas que numa regra geral ainda são maioria em número nos municípios pequenos, são também fontes variadas de conhecimento e socialização dos saberes locais. O professor de escola multiseriada mesmo com infraestrutura básica e pouco tempo transforma o espaço da escola e insere atividades ligadas á busca dos saberes locais para melhorar a relação escola/comunidade. Praticamente nos três municípios estudados todas as escolas multiseriadas têm alguma relação com a comunidade do entorno, aproveitam muitas vezes o espaço físico das comunidades, igrejas, utilizam o entrosamento dos pais para auxiliar na jardinagem e horta escolar, participam e integram ativamente aquela comunidade, pois é a ela que pertencem e é também para ela que estão preparando os seus filhos.

Nas escolas maiores, geralmente há pouco entrosamento com a comunidade, os educadores estão mais atentos as disciplinas, regras, normas, notas e menos preocupados em ensinar algo que pertença á localidade, como os costumes, a língua, formas de trabalho e sabedoria popular.

No município de Vera Cruz, a equipe pedagógica prepara constantemente seu quadro de professores com oficinas de estudo, que visam complementar as ações práticas que também são funções da escola e muitas vezes não foram repassadas nas licenciaturas. Nestas oficinas são abordados temas como a "Escola Ativa", que é um Programa instaurado no município com a idéia 


\title{
Revista Eletrônica em Gestão, Educação e Tecnologia Ambiental REGET/UFSM (e-ISSN: 2236-1170).
}

de que se aproveite todo espaço escolar fornecido pela localidade do município, e que dentro dele se trabalhe questões polêmicas como cidadania, ambiente, cultura e folclore, entre outros.

Nos outros dois municípios o item espaço escolar é pouco explorado, ficando restrito ao que define a Secretaria Municipal de Educação e repassa para a escola.

\subsection{Identidade Cultural e Saberes Locais}

A análise do espaço como campo das relações entre os próprios homens e entre os homens e o meio também tem sido realizada pela antropologia, na qual estas idéias remetem à noção de cultura local. Conceitualizar a cultura de um local e definir o que ela é, do que se constitui e como se forma tem sido uma árdua tarefa para as ciências humanas que buscam, através de conceitos antropológicos, históricos e sociais, definições mais precisas. Buscando fugir da amplidão que tange atualmente o conceito de cultura, alguns cientistas sociais têm chamado esse conceito de identidade cultural local, ou ainda de saberes locais (GEERTZ, 1989, p 15). Para Milton Santos,

\begin{abstract}
Assim como cidadania e cultura formam um par integrado de significações, também cultura e territorialidade são, de certo modo, sinônimos. A cultura, forma de comunicação do indivíduo e do grupo com o universo, é uma herança, mas também um reaprendizado das relações profundas entre o homem e o seu meio, um resultado obtido através do próprio processo de viver. Incluindo o processo produtivo e as práticas sociais, a cultura é o que nos dá a consciência de pertencer a um grupo. O território em que vivemos é mais que um simples conjunto de objetos, mediante os quais trabalhamos, moramos, é também um dado simbólico, sem o qual não se pode falar de territorialidade. Esta não provêm do simples fato de viver num lugar, mas da comunhão que com ele mantemos (SANTOS, 1988 p 83).
\end{abstract}

Durante as oficinas realizadas, os professores conseguiram reunir alguns temas de interesse ( Quadro 2) que poderiam ser inseridos na prática educativa do dia-a-dia escolar e com isso poderiam resgatar alguns dos saberes existentes nas comunidades e a partir de então convertê-los em aprendizagens significativas que poderiam gerar maior conhecimento sobre o próprio meio onde estão inseridos e assim promover uma evolução regional e um desenvolvimento de acordo com as demandas e princípios das comunidades envolvidas.

Quadro 2: Temas interesse sugeridos pelos professores para resgate dos saberes locais em cada município.

\begin{tabular}{|l|l|l|}
\hline Município & № Professores & Temas de Interesse \\
\hline Vera Cruz & 23 & $\begin{array}{l}\text { História do município, Uso de cisternas nas } \\
\text { casas, Reaproveitamento dos resíduos } \\
\text { orgânicos na horta de casa, Relações familiares } \\
\text { e o consumo, Plantas medicinais na prevenção } \\
\text { de enfermidades. }\end{array}$ \\
\hline Vale do Sol & $\begin{array}{l}\text { Cultura alemã, Resgate sementes crioulas, } \\
\text { valorização recursos naturais da localidade, } \\
\text { Agricultura Familiar e suas diversas práticas. }\end{array}$ \\
\hline & 60 & $\begin{array}{l}\text { Cultura e tradicionalismo gaúcho, Resgate do } \\
\text { Empreendedorismo, Bem estar das pessoas, }\end{array}$ \\
\hline
\end{tabular}


Revista Eletrônica em Gestão, Educação e Tecnologia Ambiental

REGET/UFSM (e-ISSN: 2236-1170).

\begin{tabular}{|l|l|l|}
\hline Candelária & 25 & $\begin{array}{l}\text { Resgate e busca pelos fósseis da cidade, } \\
\text { Conservação do Rio Pardo. }\end{array}$ \\
\hline
\end{tabular}

Fonte: Oficinas de trabalho, 2011

A tabela nos surpreende com a variedade de temas que o professores conseguiram reunir em pouco tempo de atividade. Ela demonstra claramente que há interesse e motivação por parte dos docentes em resgatar alguns saberes locais. É importante acrescentar ainda, a transformação da prática pedagógica tradicional para uma prática de livre escolha, que desenvolva a curiosidade e assim possa instigar o desejo dos alunos de melhorar a sua própria comunidade. Considera-se o papel do professor fundamental neste processo de descoberta e escolha de temas de interesse, sempre para guiar e ordenar as pesquisas de seus alunos, porém a sobrecarga de trabalho muitas vezes o limita á permanecer dentro da sala de aula. Assim a maneira mais eficiente de recuperar saberes locais em uma comunidade e levá-los até a sala de aula para serem transformados em conhecimento seria através de alguns agentes educativos, que pudessem ser capacitados para atuarem em campo, nas comunidades (cidade e interior), diagnosticar problemas sociais, observar potencialidades de determinada população, investigar a identidade cultural de cada localidade do município, identificar impactos ao ambiente, enfim, estes agentes seriam o fator de ligação entre a comunidade do município e a escola (que através da educação seria a promotora de um desenvolvimento local sustentável). Os agentes educativos por sua vez necessitariam de informações técnicas, Informações sobre o município de trabalho, Experiências escolares e também capacitações permanentes e em conjunto com o poder executivo do município sobre as perspectivas de desenvolvimento que a cidade busca e como a comunidade pode se integrar á gestão da prefeitura. Sem dúvida os profissionais mais preparados para atuarem neste espaço seriam os educadores ambientais, que com um conhecimento amplo e diverso poderiam utilizar como preceito básico a Educação Ambiental.

\subsection{Experiências de Projetos dos Municípios}

Vivemos numa era de mudanças rápidas (...) vivemos numa economia baseada no conhecimento, onde trabalhadores de bom nível educacional resistem aos comandos e exigem autonomia. Vivemos numa era de nichos de mercado, com consumidores habituados a uma alta qualidade e a uma ampla escolha. Neste ambiente as instituições burocráticas, públicas e privadas, que se desenvolveram durante a era industrial, parecem-nos cada vez mais deficientes. $O$ ambiente contemporâneo exige instituições cada vez mais flexíveis e adaptáveis (OSBORNE e GAEBLER, 1994). Com base nas palavras dos autores citados, entendemos que através da perspectiva da inovação e com métodos de criatividade na gestão de pequenos municípios é possível pensar em enfoques interdisciplinares e orientação para o desenvolvimento integrado construído sobre as bases da sustentabilidade ambiental.

- Assumir iniciativas na busca de soluções para problemas existentes no município, empoderando e focando as ações no indivíduo e não somente no coletivo.

- Pensar melhor as ações executadas e monitorá-las durante o ano. 


\section{Revista Eletrônica em Gestão, Educação e Tecnologia Ambiental REGET/UFSM (e-ISSN: 2236-1170).}

- Promover articulações com outros e novos arranjos institucionais, destacando a temática das parcerias, vínculos e alianças.

- Extensão e humanização em nossos serviços.

- Trabalhar com a participação da população nas intervenções que se queira fazer.

- Considerar as características culturais regionais, valorizando-as, incentivando-as e resgatando a utilização de tecnologias populares tradicionais.

- Implantação de redes de atores e entidades, mobilizando-os em torno de problemas e interesses públicos, pois a articulação em rede se constitui, por si só, numa inovação em relação à participação da sociedade em decisões e representações de uma comunidade. 0 que se pode considerar é que uma inovação tem uma relação direta com uma mudança.

No mundo contemporâneo, as mudanças e inovações têm grande importância na transformação e melhoria da qualidade de vida de pessoas, comunidades, vilas e povos, que caminham buscando ideais de crescente desenvolvimento, com maior justiça, oportunidades, liberdade e felicidade. Tais idéias podem ser atingidas de forma mais ou menos rápida, dependendo das concepções e das práticas gerenciadas e colocadas em ação. As mudanças alteram, criam e ampliam práticas, valores e pressupostos.

Cito nesta etapa uma experiência do município de Vera Cruz, relatada por uma gestora escolar em uma entrevista de vídeo para esta pesquisa:

Neste sentido caminham algumas escolas do município de Vera Cruz, cuja experiência e palavras relatamos:

Escola e CPM: A escola deve participar de todo o processo, ela deve em primeiro lugar questionar os pais sobre, que saber que gostariam que seus filhos aprendessem na escola além do bê-á-bá. Propomos em primeiro lugar que os pais se sintam á vontade para falar durante as assembléias e as tornamos mais freqüentes. Nestas, cada CPM tem seus líderes como também a escola os possui na figura do diretor.

Assembléias: Se pensou em assembléias, onde se mostre que no meio onde vivem existem várias coisas positivas, precisa em primeiro lugar resgatar a autoestima deles, a valorização do lugar onde vivem, só depois partir para o debate e questioná-los sobre porquê seus filhos precisam estudar para sair do interior ou porque há tanto êxodo rural. Trazer a reflexão e devolver a eles como acham que poderíamos estar contribuindo com a comunidade.

Mobilização: Penso que o primeiro passo é mobilizar os professores para que percebam que aquele espaço é deles, pois com os professores motivados vamos conseguir reproduzir as ações na comunidade escolar. Os professores precisam liderar de uma forma motivada.

Capacitação Permanente: Passamos o ano todo capacitando-os para que resgatem o trabalho nas famílias, agora no final do ano lançamos a segunda etapa do programa, mas se adere quem quiser e se sentir preparado.

Papel dos gestores escolares e professores: Acredito que muitos dos problemas que enfrentamos estão no gestor escolar, em sua resistência as coisas novas. Posso relatar a história de um menino que faltou a aula, pois seu pai precisou de sua ajuda para salvar um terneiro que estava nascendo. No outro dia a sua professora deixou-o de castigo e repetiu várias vezes que ele não podia faltar às aulas, ela não pensou em trazer o fato para dentro da sala de aula e se aproveitar do acontecido para ensinar coisas novas. 


\title{
Revista Eletrônica em Gestão, Educação e Tecnologia Ambiental REGET/UFSM (e-ISSN: 2236-1170).
}

\begin{abstract}
Dificuldades do programa: constantes mudanças no quadro de professores, mas sempre damos preferência a quem seja da localidade porque é quem melhor conhece a realidade a ser transformada.
\end{abstract}

Papel da Educação Ambiental no Desenvolvimento do Município: pode ajudar neste processo desde que o sujeito se perceba inserido na comunidade e valorize o seu trabalho perante ela e seu espaço dentro dela de maneira que sempre busque por algo mais. "Em primeiro lugar, o município é cada família, e se cada família cuidar do seu território nós já estamos evoluindo (Entrevista - Supervisora de Ensino do Município de Vera Cruz, 10/10/2011).

A elevação da qualidade de vida e a eqüidade social constituem objetivos centrais do modelo de desenvolvimento, orientação e propósito final de todo esforço de desenvolvimento no curto, médio e longo prazos. As contribuições mais significativas de alguns dos participantes qualificados sobre este aspecto destacamos nos parágrafos a seguir:

Primeiro: Citando-os literalmente, nos explicam que a princípio, a Educação Ambiental não é nada mais do que o ensino com o Meio Ambiente. Porém, também explicam que no passado, não muito distante, as maiores descobertas foram feitas observando e pesquisando a complexidade e a simplicidade do Meio Ambiente.

Segundo: Utilizando-se o ambiente como ferramenta das demais áreas da ciência, aprendemos a conviver, conhecer e respeitar o Meio Ambiente da forma em que ele se apresenta neste momento, tanto no passado e como nos projetos para o futuro. Um tipo de educação como este muda conceitos, torna a educação mais crítica e modifica hábitos que certamente mudarão a realidade da qualidade ambiental, da qualidade de vida dos seres humanos.

Terceiro: E fazendo uso das palavras de Atico Chassot (2001): Sobre o que não podemos ter dúvida, é de que não são com as ações pontuais que vamos mudar os atuais valores quanto ao ambiente, e sim qualificando os professores para que aprendam junto com os alunos a complexidade do ensino e do meio ambiente, pois os professores que estão hoje nas salas de aula não tiveram formação quanto a "alfabetizar com o Meio Ambiente".

\subsection{Educação Sócioambiental}

"O que define a Educação Socioambiental é sua responsabilidade social, seu compromisso com a solução de problemas, sua capacidade em desenvolver um enfoque compreensivo e holístico do projeto de vida do homem, abrangendo todos os níveis da experiência". (DIAS, $2005 \mathrm{p}$ 87).

Tomando-se por base as palavras de Dias (1993) pode-se afirmar segundo nos explicavam os participantes desta rodada de debates e análise dos programas institucionais de EA:

1) Do ponto de vista da produção do saber, ter uma educação específica voltada ao meio onde vivemos é fundamental para fomentar ações que levam a uma relação equilibrada entre nós e o meio ambiente.

2) Será de suma importância preparar as pessoas com conhecimentos suficientes e valores éticos que as qualifiquem para uma função social e produtiva na comunidade com uma perspectiva de melhoria da qualidade de vida e de proteção ao meio ambiente.

3) "É nítida a importância de o processo escolar atuar em conjunto com uma educação específica voltada ao meio de uma comunidade ou de um município, para que se possa formar indivíduos capazes de intervir e estimular o desenvolvimento local sustentável".

4) "A proposta deve considerar a realidade do local, estar de acordo com a cultura da população $e$ adaptada há política de desenvolvimento do município. 5) Existe a conviç̧ão de que as ações de 
Revista Eletrônica em Gestão, Educação e Tecnologia Ambiental REGET/UFSM (e-ISSN: 2236-1170).

cidadania ambiental devem começar onde se mora e se vive e só depois se estender para o restante do município".

6) "A sensibilização e a conscientização da comunidade local sobre os valores e comportamentos ambientais levarão a uma melhor convivência dos cidadãos com o meio ambiente, buscando melhorar a qualidade de vida de todos e conseqüentemente aumentando o desenvolvimento local do município".

Conseqüentemente e de acordo com as experiências coletadas durante a realização das oficinas nos três municípios, junto com os professores e gestores escolares, será necessário que se utilize estratégias sociais para eficientemente envolver a população local, o que pode ser conseguido com a capacitação de grupos da comunidade, patrulhas locais que possam atuar como agentes transformadores da realidade, por meio da Educação Ambiental.

O mapa conceitual, ferramenta e metodologia que se pode empregar no desenvolvimento dos programas de Educação Ambiental, facilita a compreensão do processo que se pretende realizar nos municípios comprometidos com programas críticos de EA e voltados para o Desenvolvimento Local.

\subsection{Proposta de Mapa Conceitual}

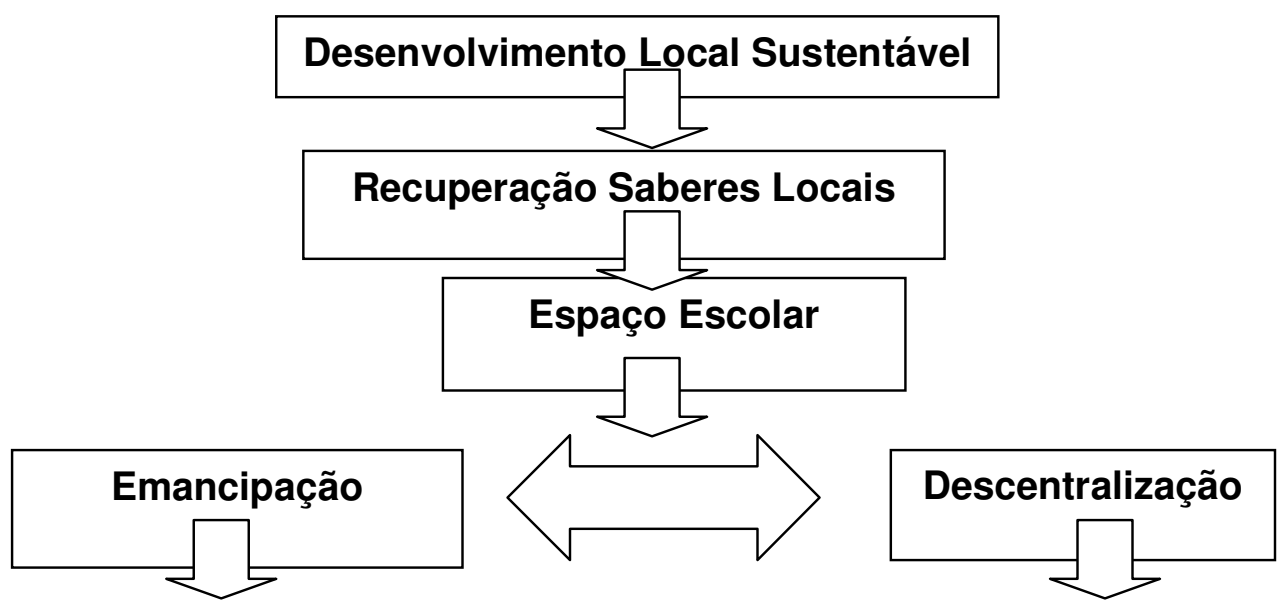

\section{Diversidade Cultural}

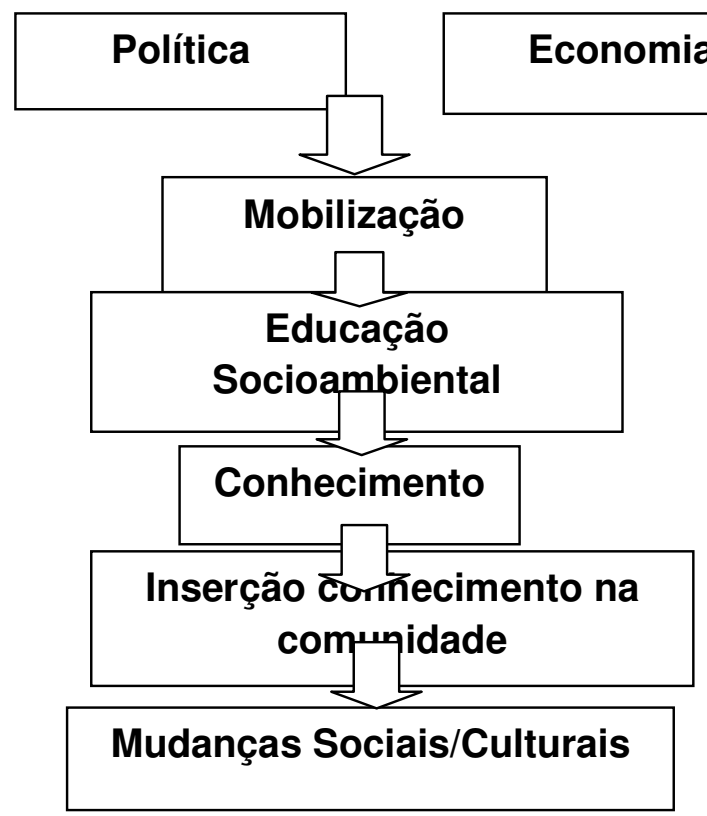




\section{Revista Eletrônica em Gestão, Educação e Tecnologia Ambiental REGET/UFSM (e-ISSN: 2236-1170).}

\subsubsection{Sugestão de Metodologia para a Gestão Educacional do Município:}

\begin{tabular}{|c|c|}
\hline $\begin{array}{l}\text { SECRETÁRIA MUNICIPAL } \\
\text { DE EDUCAÇÃO }\end{array}$ & SECRETÁRIA ADJUNTA DE EDUCAÇÃO \\
\hline $\begin{array}{l}\text { Função exclusivamente pedagógica, } \\
\text { Organizar os agentes educativos, } \\
\text { Treiná-los e integrá-los á gestão do município, } \\
\text { Organizar reuniões semanais da equipe com } \\
\text { os demais secretários, } \\
\text { Reuniões com o prefeito/a, } \\
\text { Auxiliar no exercício da função do agente em relação } \\
\text { a comunidade e escola. }\end{array}$ & $\begin{array}{l}\text { Função administrativa } \\
\text { Organizar a estrutura escolar, professores, transporte, } \\
\text { merenda... } \\
\text { Deliberar recursos, } \\
\text { Participar ativamente do exercício de gestão da escola } \\
\text { com os diretores e presidentes de COM. }\end{array}$ \\
\hline $\begin{array}{l}\text { OBS: As duas secretárias precisam interagir } \\
\text { constantemente entre si, para ajustar detalhes e } \\
\text { promover uma educação em todos os sentidos no } \\
\text { município, não somente na escola. }\end{array}$ & \\
\hline
\end{tabular}

Fonte: Elaboração da Autora

\section{CONSIDERAÇÕES FINAIS}

Depois de coletadas as diferentes experiências dos gestores escolares nos três municípios pesquisados, prevalece o entendimento de que para transformar os saberes locais em educação ambiental e projetos socioambientais que sirvam de base ao desenvolvimento de municípios será necessário capacitar alguns agentes educativos que promovam este intercâmbio de informações entre a comunidade e a escola. Assim como os Agentes de saúde possuem a função de integrar as famílias no cuidado à saúde e prevenção de enfermidades, os agentes educativos também teriam a missão de possibilitar diagnósticos da comunidade, recuperar os saberes locais e integrar este conhecimento á escola, que por sua vez seria a responsável por incluir as ações de transformação no currículo escolar.

Desta maneira, promover um Desenvolvimento Local é essencial, pois ajudar as populações envolvidas a se organizar e a se educar, para que repensem seus problemas e identifiquem as suas necessidades e os recursos naturais que estão aí envolvidos é um grande estímulo propulsor á sustentabilidade deste meio. A experiência desenvolvida ensina que cada localidade do município precisa ser compreendida como um ecossistema único que além dos aspectos gerais, considera de maneira particular os dados ecológicos e culturais do próprio local para otimizar seu aproveitamento, evitando as ações degradadoras e articulando a isto a melhoria da qualidade de vida através do incremento da produtividade, com o objetivo de manter em equilíbrio ao ecossistema onde se realizam estas atividades.

Deve-se começar pelo processo educacional, porém isto não significa que precisa ser através das escolas, afinal elas são somente uma instância da educação. Existem muitas outras instituições que precisam ser atingidas: associações de Pais e Mestres (CPM); entidades nãoformais de educação, coletivos de mulheres, terceira idade, grupos de jovens, comitês de bacia, etc. 


\section{Revista Eletrônica em Gestão, Educação e Tecnologia Ambiental REGET/UFSM (e-ISSN: 2236-1170).}

A convivência com os grupos de professores e gestores e os escritos de Barreira Filho et.al. (2004, p. 93) nos mostra que uma idéia que não podemos deixar de lado quando debatemos a nível municipal a questão do Desenvolvimento Local é que este passa pelo processo do uso dos potenciais endógenos das comunidades (saberes, experiências, tecnologias) a partir dos quais pode-se construir e gerir dialeticamente o desenvolvimento, que tenha como base fundamental a participação democrática dos membros da comunidade e a busca pela melhoria de vida dessas pessoas, respeitando o meio ambiente.

Além disso, não podemos esquecer que o lugar é o local onde ocorrem as grandes transformações, porque é vida, sentidos e sentimentos. É nele que se concretizam as relações humanas/sociais e carrega sentido de identidade e de poder, e é pelo desenvolvimento do poder que o lugar se torna território apropriado pela comunidade. O lugar é o fundamento; sem ele não existiria a sociedade. Evidencia-se, portanto que a discussão sobre Gestão e Desenvolvimento Sustentável passa sempre pelo lugar ou local.

\section{REFERENCIAS}

AZIS AB' SABER. [Entrevista concedida á Revista Nova Escola de Janeiro de 2001, publicada no site: aprendizesdanatureza.blogspot.com/.../entrevista-com-aziz-absaber.html Acesso no dia 10/11/2011.

BARREIRA FILHO, Enildo B. e FURTADO SAMPAIO, José L. (2004) Sustentabilidade Ambental: Discutindo o lugar. Em: Mercator - Revista de Geografia da UFC, ano 03, número 06, 2004. p.89-94.

BRINCKMANN, W.E. (2009). Mobilização: Ato de Colocar-se em Movimento e Multiplicar-se Multiplicando. Artigo resultado do projeto: Mobilização Social. (Re)Ordenamento Do Território E Gestão Das Águas Em Áreas Urbanas E Periurbanas Da Bacia Hidrográfica Do Rio Pardo (REDE MOBILIZA). Artigo Inédito.

BRINKMANN, W. \& MUELLER C. C. Mobilização e Formação de Educadores Ambientais: Desafios para o processo de Gestão das Águas por Bacias Hidrográficas, RS, Brasil - Apresentação no VII Congreso Ibérico sobre Gestión y Planificación del Agua "Ríos Ibéricos +10. Mirando al futuro tras 10 años de DMA" 16/19 de febrero de 2011, Talavera de la Reina - Espanha.

BUARQUE, SÉRGIO. Metodologia de Planejamento do Desenvolvimento Sustentável. Recife, IICA, 1995 (mimeo). Publicado pelo IICA como Desarrollo Sostenible - Metodología de Planeamiento Experiencias del Nordeste de Brasil. San José, Costa Rica : BMZ7GTZ-IICA , 1997a.

CAPRA, FRITJOF. As conexões ocultas: ciência para uma vida sustentável. 2. ed. São Paulo: Cultrix, 2002. $296 \mathrm{p}$.

CHASSOT, A.I. Alfabetização científica: questões e desafios para a educação. Editora Unijuí, ljuí/RS 2001.

DIAS, GENEBALDO FREIRE. 40 contribuições pessoais para a sustentabilidade. São Paulo: Gaia, 2005.

FREIRE, C. C. DE OMENA, S. P. F. Princípios de Hidrologia Ambiental In: CNPq, Ministério de Ciência e Tecnologia, CTHidro, UFSC-UFAL. Curso de Aperfeiçoamento em Gestão de Recursos Hídricos, 2009. Módulo I, p. 01-10.

FERREIRA, Manoel Rodrigues. Os escravos mecânicos. São Paulo: Nobel, 1975 


\section{Revista Eletrônica em Gestão, Educação e Tecnologia Ambiental REGET/UFSM (e-ISSN: 2236-1170).}

FREIRE, PAULO. Educação e Participação Comunitária. Editora Inovação, São Paulo, 1996, pag. 312.

GAJARDO, M. Pesquisa participante: propostas e projetos. In: BRANDÃO, C.R. (org) Repensando a Pesquisa Participante. São Paulo: Brasiliense, 1999.

GEERTZ, Clifford. A Interpretação das Culturas. Editora Guanabara, Rio de Janeiro. 1989.

JACOBI, PEDRO (2003). Educação ambiental, cidadania e sustentabilidade. Cad. Pesquisa, São Paulo, $n$. 118, 2003. Disponível em: <http://www.scielo.br/scielo >. Acesso em: 20/10/2010.

JACOBI, Pedro Roberto; PINHO, José Antonio (Org.). Inovação no campo da gestão pública local: novos desafios, novos patamares. Rio de Janeiro: Fundação Getúlio Vargas, 2006. 204 p.

LAYRARGUES, P.P. (Re)conhecendo a educação ambiental brasileira (apresentação). In: Ministério do Meio Ambiente. Identidades da Educação Ambiental Brasileira. Brasília: Edições MMA. 2004.

MEDINA, NANÁ MININNI. A Formação dos Professores em Educação Ambiental In: Oficina Panorama de Educação Ambiental no Brasil (28 e 29 de março de 2000) MEC/SEF; Coordenação-Geral de Educação Ambiental.

SATO, Michèle; SANTOS, José Eduardo. Tendências nas pesquisas em educação ambiental. In NOAL, F.; BARCELOS, V.; REIGOTA, M. (Orgs.) Construindo a Educação Ambiental. Santa Cruz do Sul, EDUNISC, 2003 (no prelo).

MOLL, J. Histórias de Vida, histórias de escola: elementos para uma pedagogia da cidade. Petrópolis: Vozes, 2000

MORIN, EDGAR. O método: 0 conhecimento do conhecimento. Volume 3, Publicações Europa-América, 1992.

OSBORNE, D., GAEBLER, T. Reinventando o Governo. Brasília: MP Comunicações, 1994.

PHILIPPI, ARLINDO J. \& PELICIONI, MARIA C.F. Educação Ambiental: Desenvolvimento de Cursos e Projetos. 2a Edição, Editora Signus, Universidade de São Paulo: Faculdade de Saúde Publica, Núcleo de Informações em Saúde Ambiental, 2002.

QUINTAS, JOSÉ SILVA. Introdução à gestão ambiental pública / 2ª ed. revista. Brasília: Ibama, 2006.

PALESTRA DE JOSÉ PACHECO, A Metodologia da Escola da Ponte. Proferida através de videoconferência para a Universidade de Santa Cruz do Sul - UNISC em 21/09/2011.

REVISTA PLANETA: Mundo Superlotado Somos 7 Bilhões e Agora? Edição 465 Junho de 2011, São Paulo, Editora Três Ltda, Pág 7 a 9.

THIOLLENT, MICHEL et al Metodologia da Pesquisa-Ação 5ạ Edicão, Editora Cortez, São Paulo, 1992.

SANTOS, Milton. Espaço do Cidadão. Editora Nobel, São Paulo, 1988.

VASCONCELOS, C. S. Avaliação da Aprendizagem: Práticas de Mudanças por uma Práxis Transformadora. Editora Liberdad, São Paulo, 1998.

VALE DO SOL (RS) Prefeitura. Plano Ambiental do Município. Elaborado em 2009, pág. 57. 